\title{
Incidence of Mammary Tumour and Venereal Granuloma in Canine in Durg District Chhattisgarh, India
}

\author{
Nutan Panchkhande, Rukmani Dewangan*, M.O. Kalim, R. Sharda, H.K. Ratre, \\ Dhlaeshwari Sahu, Shiv Sidar and S.K. Yadav
}

Department of Veterinary Surgery and Radiology, College of Veterinary Science, Anjora, Durg (C.G.), India

*Corresponding author

\begin{abstract}
A B S T R A C T
The present study was conducted to know the incidence of mammary tumour and venereal granuloma in canine from August 2017 to July 2018 and only clinically suspected cases of

\section{Keywords}

Canine, Incidence, Mammary tumour, Venereal granuloma

Article Info

Accepted:

17 March 2019

Available Online:

10 April 2019 tumour were presented to Department of Veterinary Surgery and Radiology, College of Veterinary Science \& A.H., Anjora, Durg (C.G.). Out of 25 cases, 18 cases of mammary tumours and venereal granuloma in male and female dogs of different age group and different breeds were selected for this study. The highest incidence of mammary tumour and venereal granuloma were observed in 4 to 7 years of age group. Higher incidence of tumour was observed in nondescript (38.88\%) followed by Pomeranian (16.67) and Labrador (16.67\%). All affected dogs were unspayed and uncastrated. Highest percent of tumour was observed on mammary gland $(50 \%)$ followed by vagina $(33.33 \%)$ and penis $(16.66 \%)$. The occurrence of mammary tumour was more in $5^{\text {th }}$ gland $(16.66 \%)$ followed by $4^{\text {th }}$ to $5^{\text {th }}$ gland $(11.11 \%), 4^{\text {th }}$ gland $(11.11 \%)$ and $3^{\text {rd }}$ to $4^{\text {th }}$ gland $(11.11 \%)$. The occurrence of venereal granuloma was more in vagina/vulva $(33.33 \%)$ followed by base of penis/glans penis $(16.66 \%)$. The size of tumour between 3 to $8 \mathrm{~cm}$ and below $3 \mathrm{~cm}$ observed were more (44.44\%) as compared to over $8 \mathrm{~cm}(11.11 \%)$. Mammary tumour and venereal granuloma were observed more in female as compared to male.
\end{abstract}

\section{Introduction}

A tumour is a disturbance of growth characterized by excessive, uncontrolled proliferation of cells which may show marked variation in the biological behaviour. Cancer is one of the major causes of death in dogs and its incidence is still increasing, particularly in developing countries. Among all species, dog develops tumours twice as frequently as humans, with incidence of skin and mammary tumours being the highest (Nair et al., 2007). Mammary tumour is the most common malignant tumours account for approximately $50 \%$ of all neoplasms in female dogs (Dileepkumar et al., 2014). They occur also in male dogs, but the prevalence is only 1\% (Rutterman et al., 2000). The age group at which mammary tumours occurred most frequently was 8-10 years followed by 
10-12 years (Kishor et al., 2016). Venereal granuloma is a tumour, which has the highest percentage of incidence in canines and appears as cauliflower like growth on the external genitalia which is pedunculated, nodular, papillary or multilobulated tumour masses, which may sometimes show bleeding and serosanguineous discharge from preputial orifice in the male while in the female from genital canal. Tumour size ranges from millimeters to several centimeters with dark red to grayish pink coloration. The tumour is usually seen in young (2-5 years), sexually active dogs from an environment with high concentration of free roaming dogs with uncontrolled reproduction. Females are most susceptible than males (Gandotra et al., 1993).

There is meagre information available regarding incidence of mammary tumour and venereal granuloma in canine in different geographical location of Durg district Chhattisgarh. Therefore, the present study is aimed to provide data on incidence of mammary tumour and venereal granuloma in canines.

\section{Materials and Methods}

The present study was observed on the 25 clinically suspected cases of tumour in dog presented at the Teaching Veterinary Clinical Complex (TVCC) and Department of Veterinary Surgery and Radiology, College of Veterinary Science \& A.H., Anjora, Durg (C.G.). Out of 25 cases, 18 cases with history of mammary tumour and venereal granuloma were selected for the study during the period from January 2018 to July 2018. The incidence of tumour was studied on the basis of age, sex, breed, location/affected site, body weight, duration of illness, reproductive status and clinical examination of animals for location, size of tumour and visual examination.

\section{Results and Discussion}

\section{Age wise distribution of mammary tumour and venereal granuloma}

Age wise distribution of dogs affected with mammary tumour and venereal granuloma are shown in Figure 1. The age of all the dogs affected with tumour in the present study were ranged from 6 months to 8 and above years. Higher incidence of mammary tumour and venereal granuloma were found in dog aged between 4 to 7 years $(38.88 \%)$. The canine mammary tumors and venereal granuloma were highest recorded in the age group of 4 to 7 year (38.88\%) followed by 2 to 4 years $(27.77 \%), 8$ years and above $(22.22 \%)$ and 6 months to 2 years $(11.11 \%)$.

Similarly, Mahopatra et al., (2005), Egenvall et al., (2005), Sowbharenya et al., (2016) and Lather et al., (2017) reported the highest incidence of mammary tumour in age group between 6-7 year. Priya et al., (2006) also recorded greatest incidence of mammary tumours in the age group of 7 to 8 years. An increase in the incidence of mammary tumours was observed after 4 years of age, so called onset of "cancer age" in the present study.

Das et al., (1991) and Prasad et al., (2007) reported that CTVT mainly occurs in young (2-5 years of age), sexually mature animals. Eze et al., (2007) observed that TVT generally occurs in animals aged 2-8 years and it is more common in female dog than male dogs. In contrary to present study, Shiju Simon et al., (2016) reported that the highest incidence of transmissible venereal tumour in dog at age group of 2 - 3 years (22.01 percent) followed by 3-4 years (17.61 percent). The CTVT was most prevalent in adult middleaged dog in the present study which could be because the adult middle-aged dogs are more sexually over active. 
Breed wise distribution of mammary tumour and venereal granuloma

Breed wise distribution of dogs affected with mammary tumour and venereal granuloma are shown in Figure 2. The highest incidence of mammary tumour and venereal granuloma was observed in Nondescript (38.88\%) followed by Labrador (16.66\%), Pomeranian (16.66), German shepherd (11.11\%), Golden Retriver (5.55\%), Labrador (16.66), Lasa Apso (5.55\%), Crossbred (5.55\%) breeds of dog.

This affection was found commonly in nondescript breeds, particularly in free roaming dogs. During oestrus period mating of dogs with affected bitches is factor for spreading of the disease. It was presumed that well maintained dogs of recognized breed do not suffer with venereal granuloma as owners are aware about canine diseases.

Priya et al., (2006) recorded highest percentage of incidence of mammary tumours in the German Shepherd $(24.13 \%)$ followed by Non-descript $(22.41 \%)$ dogs. Whereas, Shivani (2007) and Kishor et al., (2016) recorded that the breed-wise occurrence of mammary neoplasms revealed highest number of tumours in Pomeranian (35\%) followed by German Shepherd (20\%) and minimal risk seen in nondescript breed Similarly, Khan et al., (2009) reported that high incidence of venereal granuloma in nondescript dog.

Shiju Simon et al., (2016) observed the incidence of venereal tumour more in nondescript dogs (38.84 per cent). In the present study, the highest incidence of mammary tumour and venereal granuloma was observed in nondescript which could be due to the fact that the population of non-descript dog is more and these dogs are not confined and are free roaming.
Reproductive status wise distribution of mammary tumour and venereal granuloma

Reproductive status wise distribution of dogs affected with mammary tumour and venereal granuloma are shown in Figure 3. The incidence of mammary tumour and venereal granuloma were recorded in unspayed and uncastrated dogs. The percentage regarding unspayed/ intact was $77.77 \%$ and uncastrated was $22.22 \%$. Generally, the incidence of venereal granuloma is more common in sexually active $\operatorname{dogs}$ and is normally transmitted during coitus (Tella et al., 2004). In the present study, the incidence of venereal granuloma was more in intact/unspayed/uncastrated dogs because of indiscriminate sexual activity which are high in stray and nondescript dogs. Similarly, Dhami et al., (2010) reported high incidence of mammary tumour in females, that too intact, as compared to male dogs which could be attributed to endocrinological and functional differences in the either sexes. In the present study, the incidence of mammary tumour was more in intact/unspayed, uncastrated dogs. Thus, it could be inferred that unspayed bitches have greater risk for occurrence of mammary tumours as compared to spayed ones. The reason could be hormone dependency of proliferating neoplastic cells. This is further supported by the observation of temporary regression of already existing mammary tumours after spaying. Alenza et al., (2000) also reported that intact females had a 3 to 7-fold greater risk of developing mammary tumours than neutered females.

\section{Sex wise distribution of mammary tumour and venereal granuloma}

Sex wise distribution of dogs affected with mammary tumour and venereal granuloma are shown in Figure 4. The incidence of mammary tumour was observed more in female $(44.44 \%)$ as compared with male 
(5.55\%). The incidence of venereal granuloma was observed more in female $(33.33 \%)$ as compared with male $(16.66 \%)$. The present study revealed that occurrence of mammary tumour was more in female as compared to male. Similar findings were recorded by Rutterman et al., (2000), Nithya (2006) and Dhami et al., (2010) reported that higher incidence of mammary tumours were more in female dogs as compared to male dog. Palta (2000), Bala (2005) and Gupta et al., (2012) reported mammary tumour in one male dog. In fact, canine mammary tumour are specific tumours in females and are rare in males and are often associated with hormonal abnormalities (Moulton et al., 1970).

This could be due to action of ovarian hormones (estrogens and progesterone) on mammary gland tissue during different stages of development which could be risk factors associated with the development of mammary tumours (Petrov et al., 2014). The risk of developing mammary tumour increase as the number of oestrous cycles increases. Similarly, Sorenmo et al., (2011) also reported that the mammary neoplasms are the most common neoplasm in female dogs. Highest incidence of mammary tumour was recorded only in females (60 cases) and 3 cases were seen in male dogs (Dhami et al., 2010). The incidence of venereal granuloma was found more in females as compared to males because of indiscriminate sexual activity which are high in stray and nondescript dogs. If male is affected with venereal granuloma which through coitus are transmitted in females and such recipient females later on acts as the donor. Similarly, Ganguly et al., (2016) and Shiju Simon et al., (2016) reported that female dogs are more affected with TVT then male because only one infected male often mates with numerous females. Whereas, Khan et al., (2009) observed that more number of males was affected with venereal granuloma as compared to females in non-descript breeds.

\section{Location wise distribution of mammary tumour and venereal granuloma}

Location wise distribution of dogs affected with mammary tumour and venereal granuloma are shown in Figure 5. The highest incidence of mammary tumour was recorded in $5^{\text {th }}$ gland (inguinal $16.66 \%$ ) followed by $4^{\text {th }}$ to $5^{\text {th }}$ gland $(11.11 \%), 4^{\text {th }}$ gland $(11.11 \%)$ and $3^{\text {rd }}$ to $4^{\text {th }}$ gland $(11.11 \%)$. In female, the incidence of venereal granuloma was recorded more in vagina/vulva $(33.33 \%)$ as compared to male at base of penis/tip of penis/glans penis $(16.66 \%)$. The above findings corroborated well with the observations of Shafiee et al., (2013), Dileepkumar et al., (2014) and Lather et al., (2017) who reported maximum occurrence in $5^{\text {th }}$ inguinal mammary gland. The present study, revealed that mammary tumours are most commonly found in $5^{\text {th }}$ gland followed by $4^{\text {th }}$ to $5^{\text {th }}$ gland, $4^{\text {th }}$ gland and $3^{\text {rd }}$ to $4^{\text {th }}$ gland probably because of their greater size containing more mammary tissue and these may be subjected to a greater range of physiological changes, predisposing them to neoplasms. Similarly, Sowbharenya et al., (2016) also observed that inguinal pair and cranial abdominal pair of mammary gland were the most commonly affected, followed by caudal abdominal and thoracic mammary gland. In present study, the incidence of venereal granuloma was recorded more in female at vagina/vulva whereas in male at base of penis/tip of penis/glans penis. Similarly, Nak et al., (2005) reported venereal granuloma in male at penis and prepuce and in female the affected site was vulva and vagina. Kose et al., (2013) also observed that venereal granuloma was located in vulva and expanded through vagina. Sharma et al., (2011) reported cases of canine transmissible venereal tumours in $10 \mathrm{dogs}$ involving penis and prepuce. Stockman et al., (2011) reported 
that the tumour is commonly located in the caudal part of the penis, the glans, and occasionally in the foreskin.

\section{Body weight wise distribution of mammary tumour and venereal granuloma}

Body weight wise distribution of mammary tumour and venereal granuloma are shown in Figure 6. The highest incidence mammary tumour and venereal granuloma was recorded in 15 to $25 \mathrm{~kg}$ body weight $(50 \%)$ followed by 8 to $15 \mathrm{~kg}$ body weight $(27.77 \%)$ then 25 to $35 \mathrm{~kg}$ body weight (22.22\%). Gupta et al., (2012) observed maximum incidence of mammary tumour $(21.57 \%)$ in dogs having body weight between $5-10$ and $30-35 \mathrm{~kg}$, followed by those having $20-25 \mathrm{~kg}, 25-30 \mathrm{~kg}$ and the minimum in dogs having weight between $0-5 \mathrm{~kg}(3.92 \%)$. These finding are similar to human being as obese females are at more risk of developing breast cancer and the results of above study may be important since dogs are considered as natural animal model to study breast cancer. The incidence and correlation of venereal granuloma with body weight could not be established and literature regarding this could not be traced out.

\section{Duration of illness Wise Distribution of Mammary Tumour and Venereal Granuloma}

Duration of illness wise distribution of dogs affected with mammary tumour and venereal granuloma are shown in Figure 7. During the study, the duration of illness was also recorded. The higher percent of duration of illness in affected dogs was observed between 3 to 6 months $(55.55 \%)$ followed by 0 to 3 months (44.44\%). Agrawal (2016) documented higher incidence of duration of illness in animal under 3-6 months which could be because of insignificant size of tumour at early stage of development. The dogs have a hairy coat and therefore many a times, the mammary tumours go unnoticed as they do not cause major symptoms in early stages. In the present study, duration of illness was recorded between 3 to 6 months followed by 0 to 3 months. The incidence of tumour was more in nondescript dog and they are often neglected by owners. Therefore, late reporting of dogs for treatment of mammary tumour and venereal granuloma was observed. Many times, tumours are not observed by owner due to their locations and hair coat due to owner's negligence and also such tumour do not cause any health problems in dogs during early stage of its development.

\section{Clinical examination}

Routine clinical examination of all the dogs affected with mammary tumour and venereal granuloma are shown in Table 1.

\section{Location and size of tumour}

In the present study, highest percent of tumour was observed on mammary gland $(50 \%)$ followed by vagina $(33.33 \%)$ and penis $(16.66 \%)$. The mammary tumour was more in $5^{\text {th }}$ gland $(16.66 \%)$ followed by $4^{\text {th }}$ to $5^{\text {th }}$ gland $(11.11 \%), 4^{\text {th }}$ gland $(11.11 \%)$ and $3^{\text {rd }}$ to $4^{\text {th }}$ gland (11.11\%) (Fig. 8). The size of tumour between 3 to $8 \mathrm{~cm}$ and below $3 \mathrm{~cm}$ observed were more $(44.44 \%)$ as compared to over 8 cm (11.11\%). Dileepkumar et al., (2014) and Lather et al., (2017) who reported maximum occurrence in $5^{\text {th }}$ inguinal mammary gland probably because of their greater size containing more mammary tissue and these may be subjected to a greater range of physiological changes, predisposing them to neoplasms. Similarly, Nak et al., (2005) reported venereal granuloma in male at penis and prepuce and in female the affected site was vulva and vagina. Kose et al., (2013) also observed that venereal granuloma was located in vulva and expanded through vagina. 


\section{Visual examination of tumour}

The ulcerative tumour was observed in 6 cases $(33.33 \%)$ followed by and nonulcerative in 6 cases $(33.33 \%)$, 2 cases was smooth (11.11\%) and four cases were intact (22.22\%) (Fig. 9). Tumour size ranged from millimetres to several centimetres. The shape of mammary tumour varied from ovoid, elongated, rounded to irregularly nodular. Most of the tumours were circumscribed and pedunculated. Grossly, tumour was soft to firm in consistency. Similar observations were recorded by Manjunatha et al., (2013) and Dileepkumar et al., (2014).

Table.1 Showing location, size and visual examination of mammary tumour and venereal granuloma in canine

\begin{tabular}{|l|l|c|c|}
\hline Clinical parameters & & Number & Percentage (\%) \\
\hline \multirow{4}{*}{ Location } & Mammary gland & 9 & $50 \%$ \\
\cline { 2 - 4 } & Vagina & 6 & $33.33 \%$ \\
\cline { 2 - 4 } & Penis & 3 & $16.66 \%$ \\
\hline \multirow{3}{*}{ Size of tumour } & Below 3 cm & 8 & $44.44 \%$ \\
\cline { 2 - 4 } & 3 to 8 cm & 8 & $44.44 \%$ \\
\cline { 2 - 4 } & More than 8 cm & 2 & $11.11 \%$ \\
\hline \multirow{2}{*}{$\begin{array}{l}\text { Visual examination } \\
\text { tumour }\end{array}$} & of & 6 & $33.33 \%$ \\
\cline { 2 - 4 } & Ulcerative & 6 & $33.33 \%$ \\
\cline { 2 - 4 } & Non-ulcerative & 2 & $11.11 \%$ \\
\cline { 2 - 4 } & Smooth & 4 & $22.22 \%$ \\
\hline & Intact & & \\
\hline
\end{tabular}

Fig.1

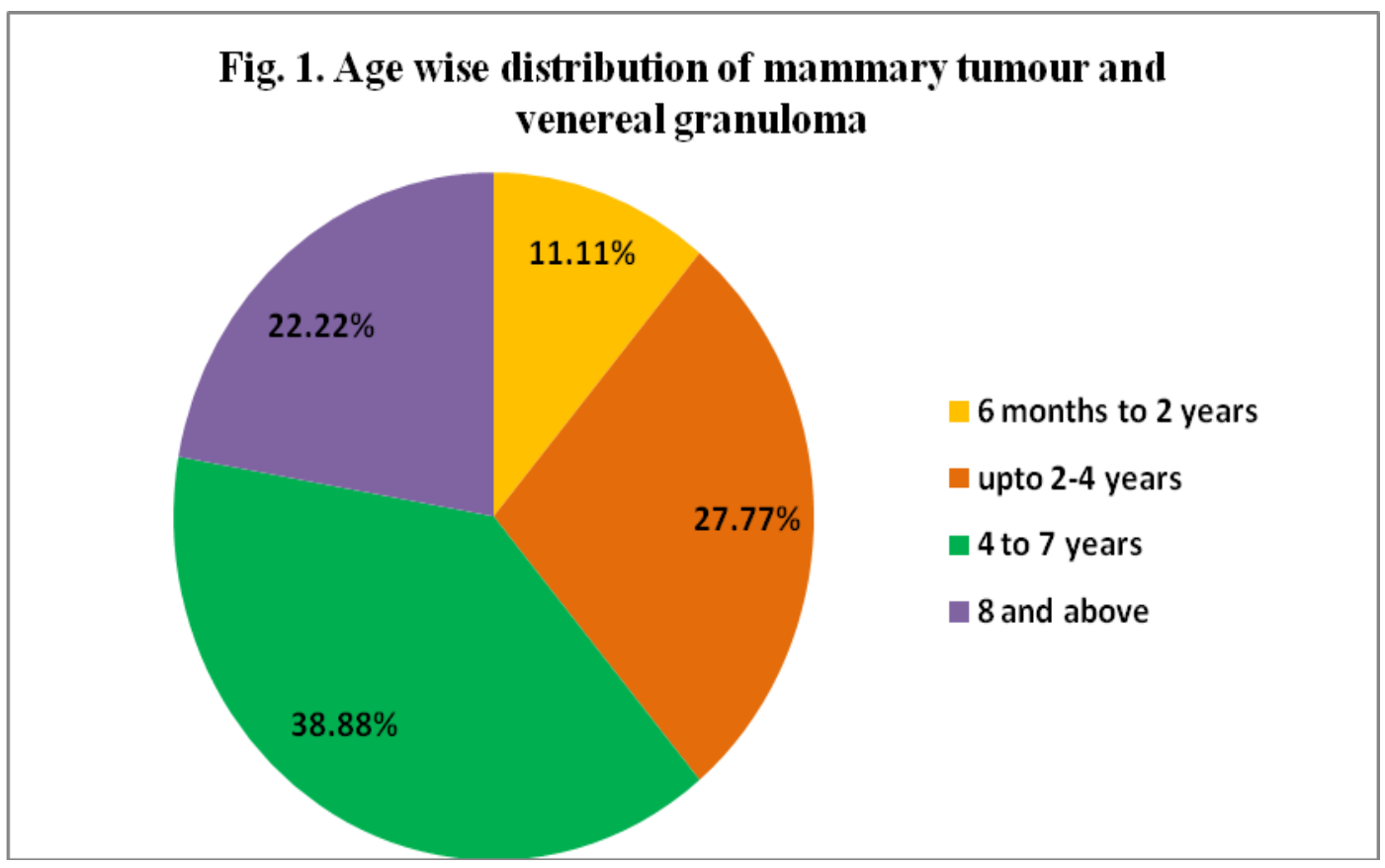


Fig.2

Fig. Breed wise distribution of mammary tumour and venereal granuloma

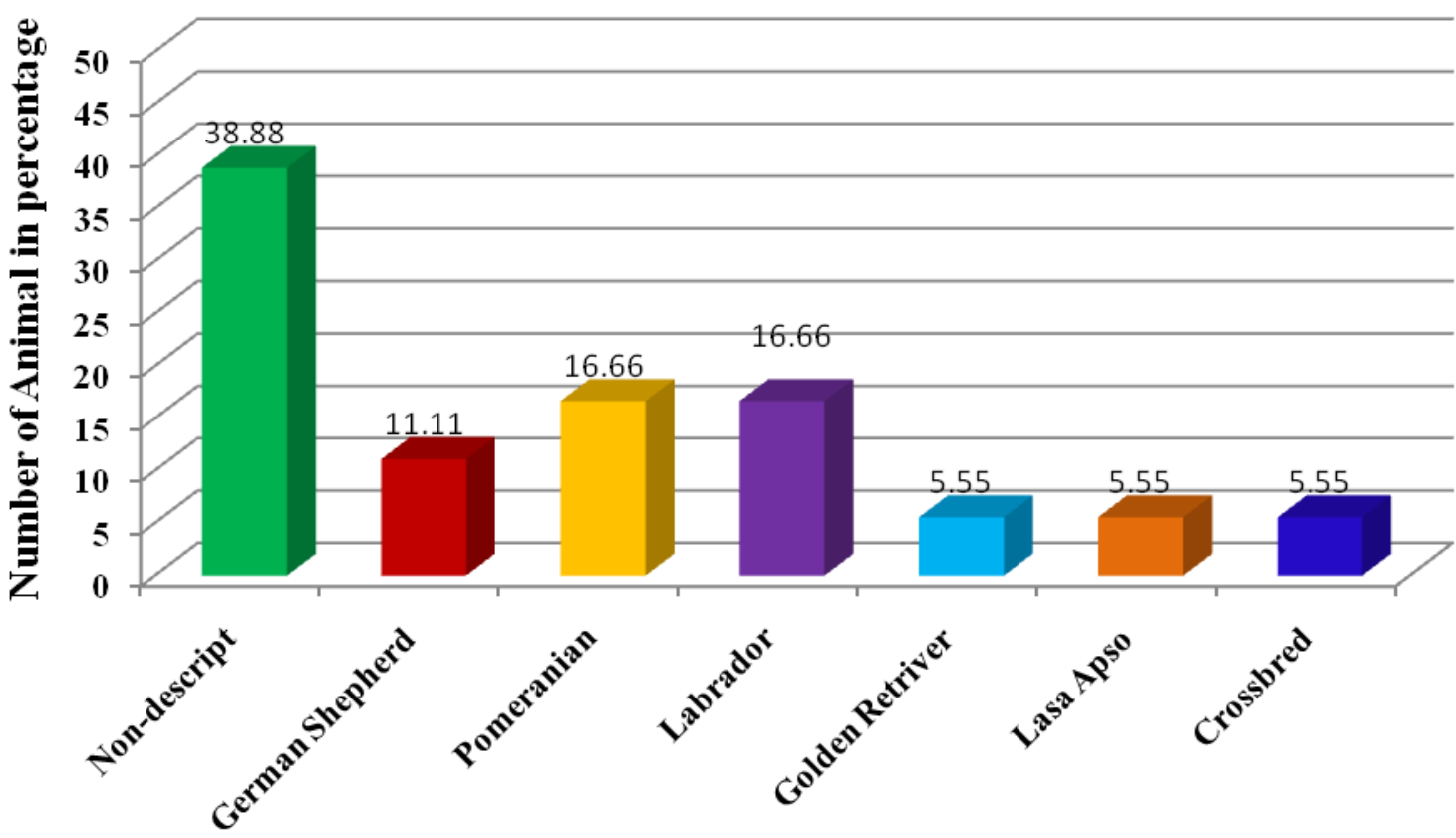

Different breed of dog

Fig.3

Fig. 3. Reproductive status of animal affected with mammary tumour and venereal granuloma

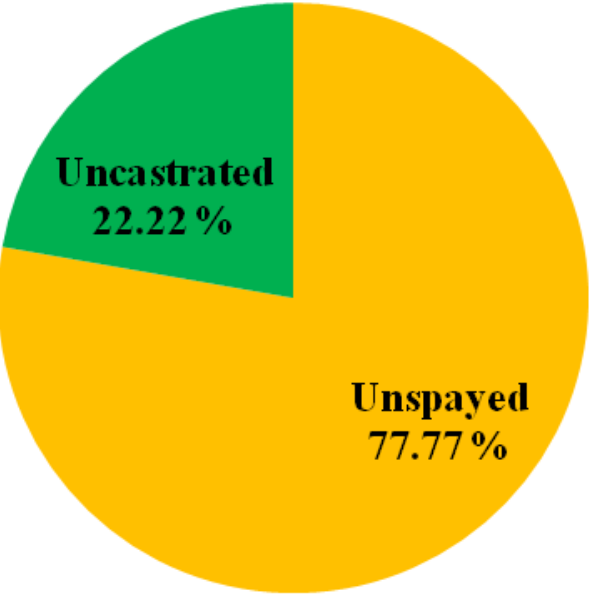


Fig.4

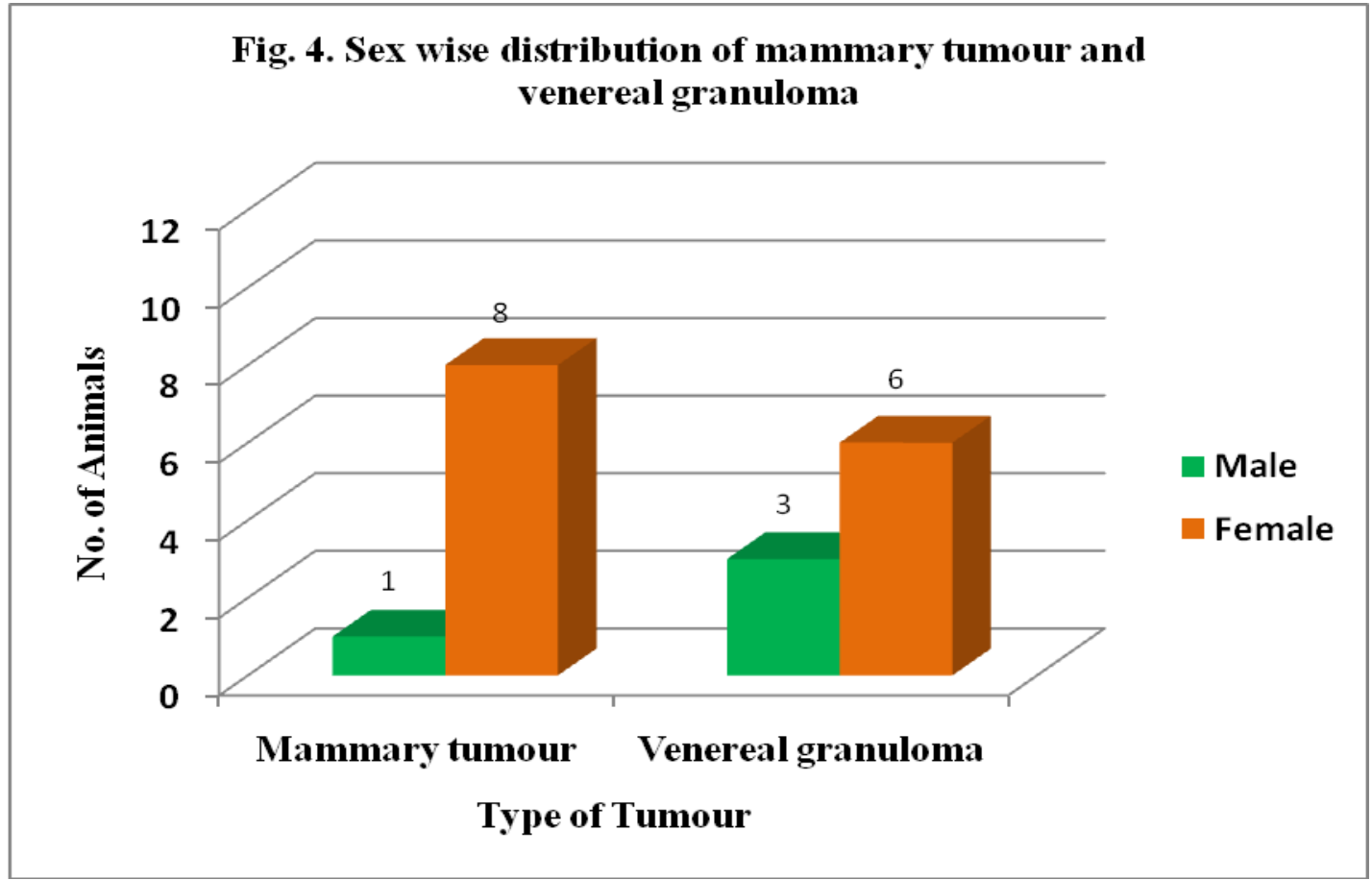

Fig.5

Fig. 5. Location wise distribution of mammay tumour and venereal granuloma

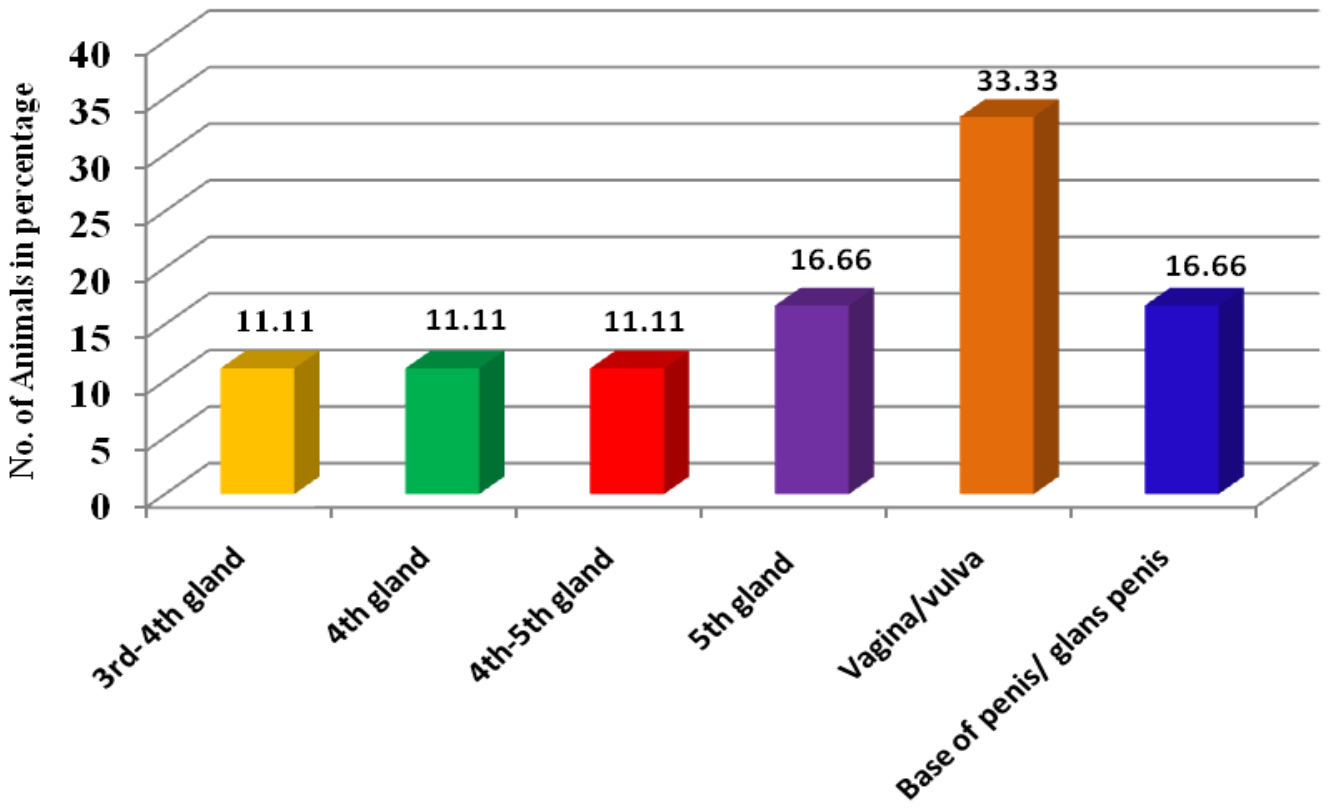

Location of tumour 
Fig.6

Fig. 6. Body weight wise distribution of animal suffering from mammary tumour and venereal granuloma

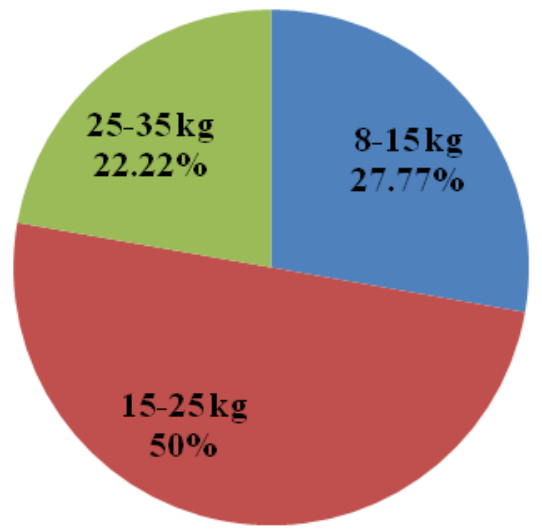

Fig.7

Fig. 7. Duration of illness suffering from mammary tumour and venereal granuloma

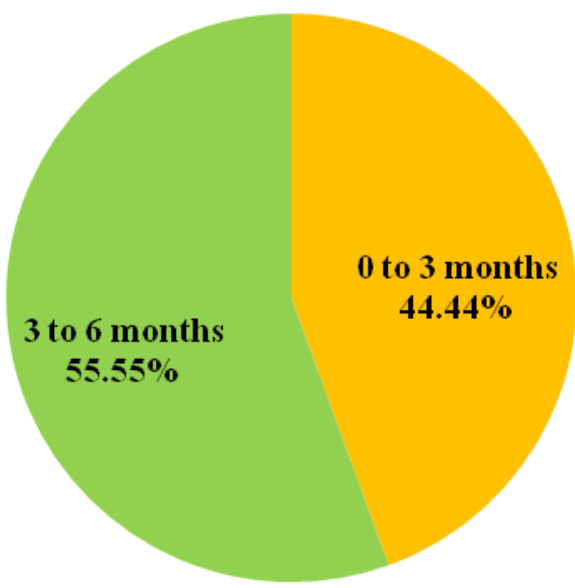


Fig.8 Showing location of mammary tumour and venereal tumour

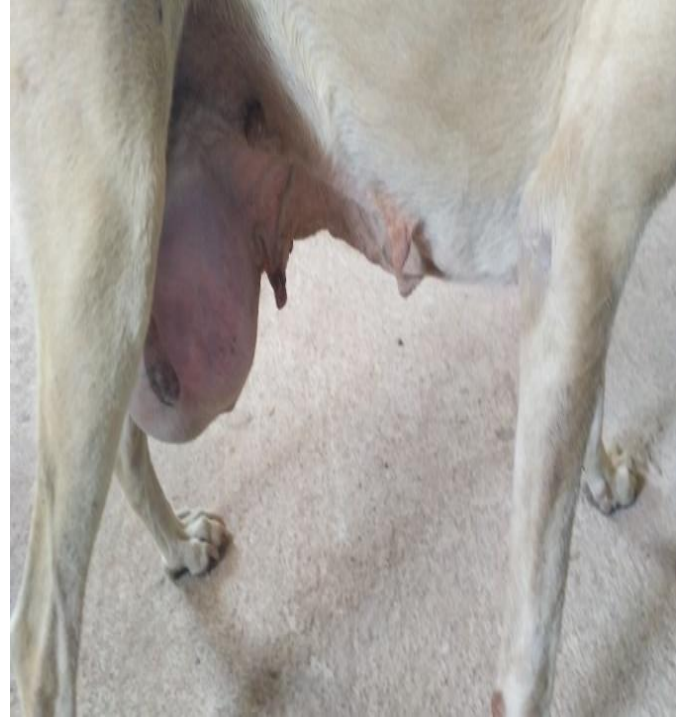

A. Intact mammary tumour involving $5^{\text {th }}$ inguinal gland

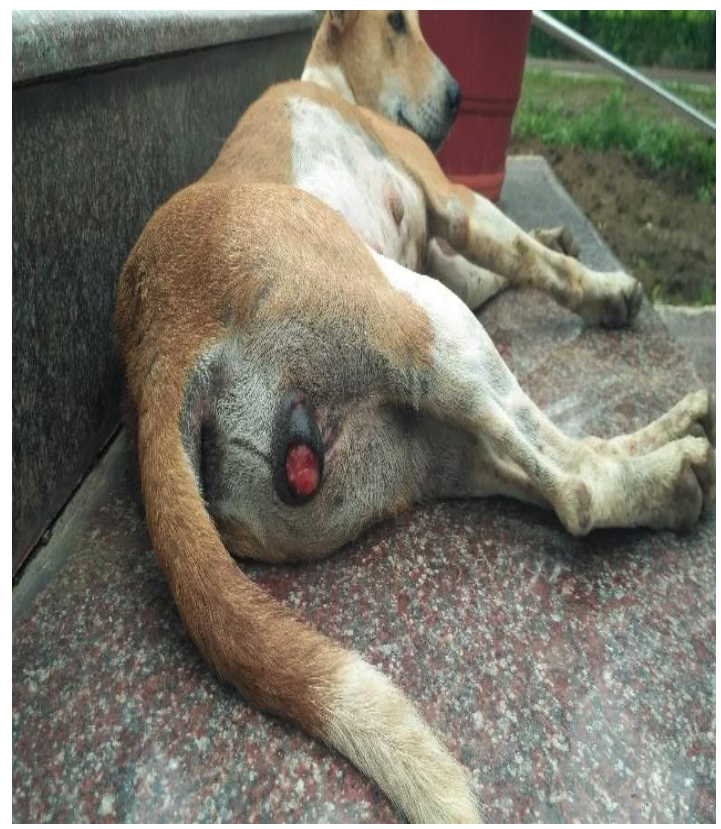

C.Cauliflower like granulomatous mass protruding from vulva

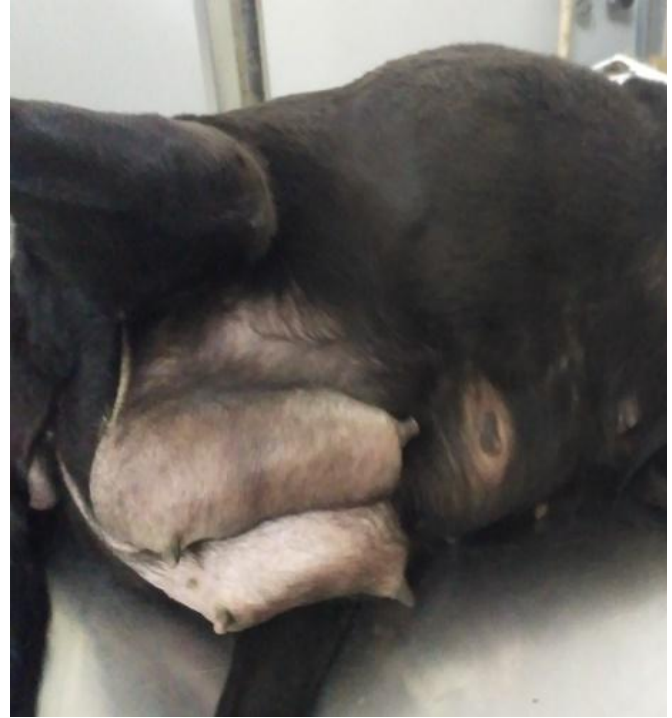

B. Mammary tumour involving both $4^{\text {th }}$ and $5^{\text {th }}$ mammary gland

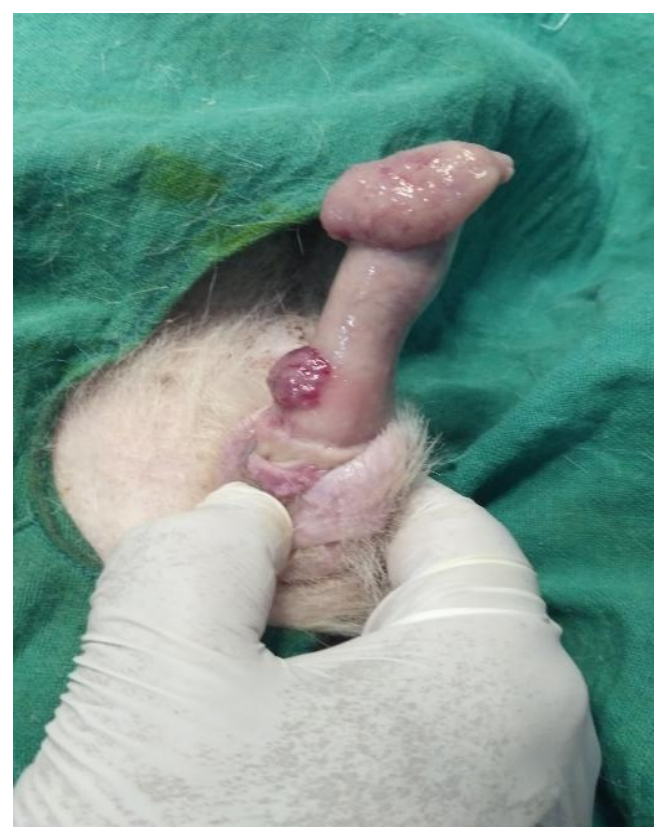

D. Nodular growth on shaft and tip of penis 
Fig.9 Showing visual examination mammary tumour and venereal granuloma

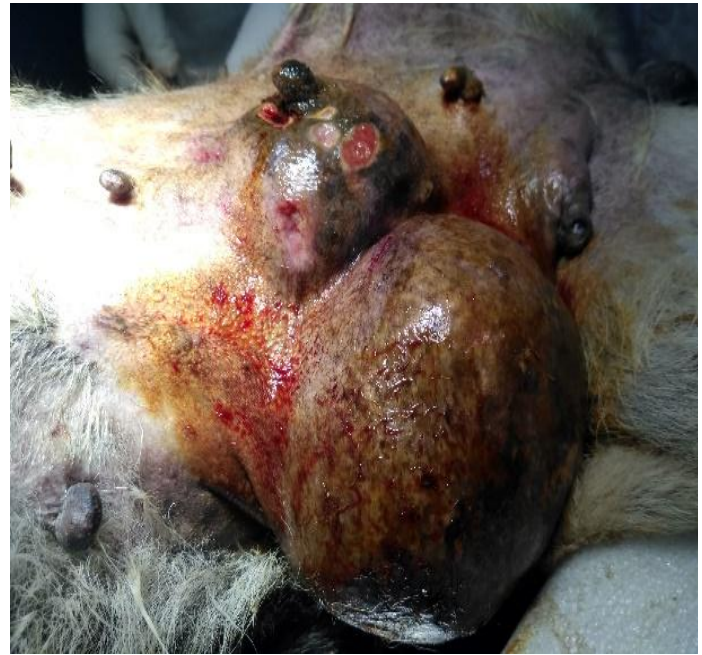

A. Ulcerative mammary tumour with maggots in female dog

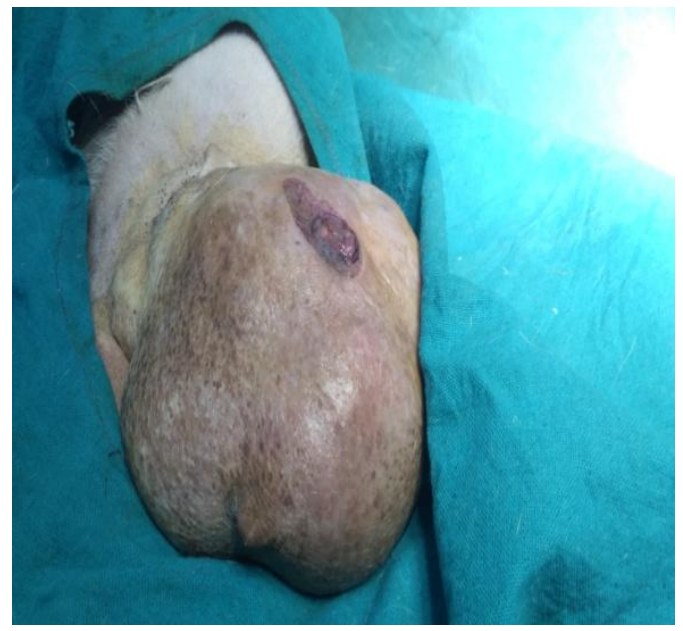

C.Intact mammary tumour in female dog

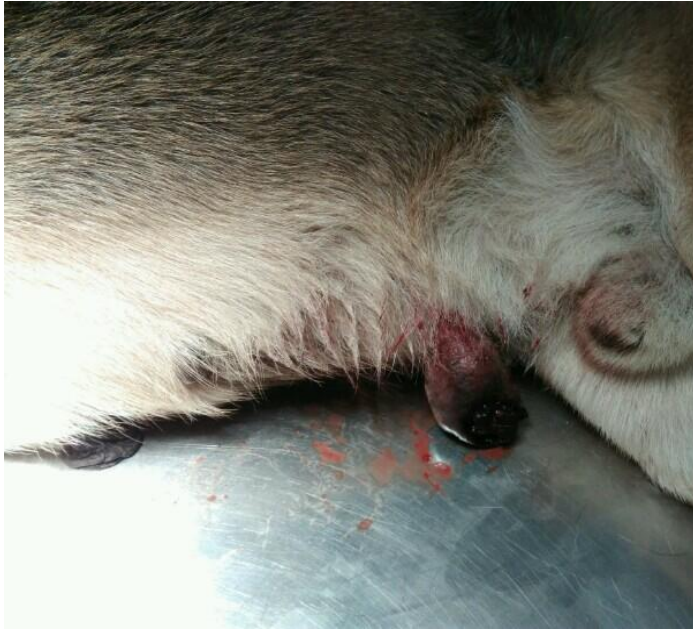

B. Ulcerative mammary tumour with maggots in male dog

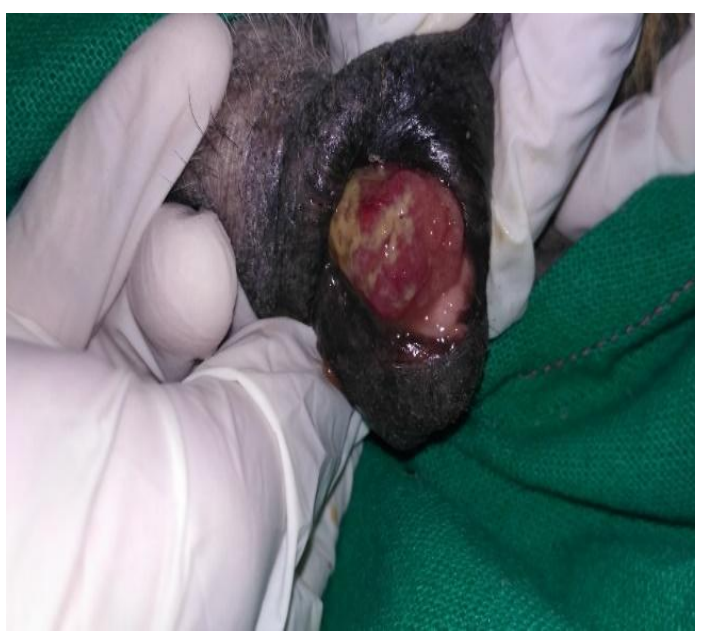

D.Ulcerative venereal granuloma in female dog

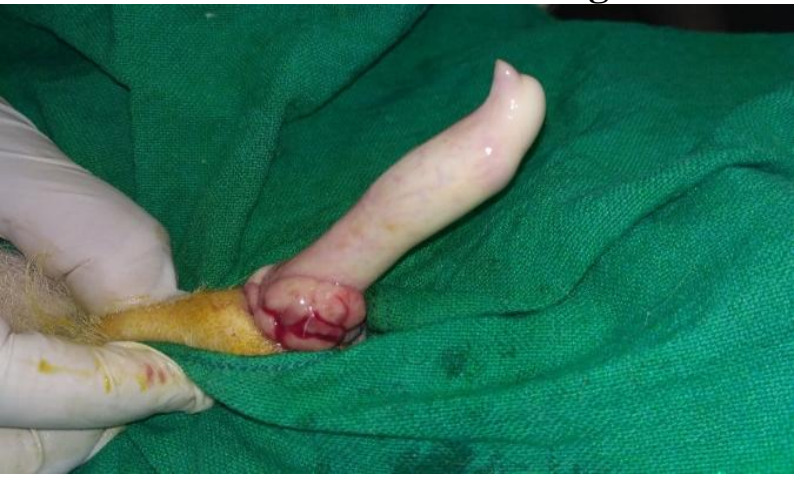

E. Smooth venereal granuloma in male dog 
The gross appearance of venereal granuloma revealed irregular cauliflower like reddish tumour mass protruding out from vulva and vagina. Multilobulated, cauliflower like, pedunculated and friable mass was observed on base of penis after retracting the prepuce. The surface were ulcerated, inflamed and bleed easily. Similar findings were recorded by Kisani and Adamu (2009) and Chandratre et al., (2017).

Therefore, on the basis of above study, it was concluded that higher incidence of mammary tumour and venereal granuloma was observed in nondescript $(38.88 \%)$ followed by Pomeranian (16.67) and Labrador (16.67\%). All affected dogs were unsprayed and uncastrated and were more in female as compared to male. The occurrence of mammary tumour was more in $5^{\text {th }}$ gland $(16.66 \%)$ followed by $4^{\text {th }}$ to $5^{\text {th }}$ gland $(11.11 \%), 4^{\text {th }}$ gland $(11.11 \%)$ and $3^{\text {rd }}$ to $4^{\text {th }}$ gland $(11.11 \%)$. The occurrence of venereal granuloma was more in vagina/vulva (33.33\%) followed by base of penis/glans penis (16.66\%). This study may serve as pioneer work for area of Durg, Chhattisgarh particular to canine mammary tumour and venereal granuloma which could be useful for further research.

\section{References}

Agrawal, B. K. 2016. Studies on nanoparticle assisted methotrexate for therapeutic management of mammary tumours in dog, M.V.Sc. thesis submitted to Maharashtra Animal and Fishery Sciences University, Nagpur.

Alenza, D. P., Pena, L., Castillo, D. N. and Nieto, I. A. 2000. Factors influencing the incidence and prognosis of canine mammary tumours. J. Small Anim. Pract., 41:287-291.

Bala, M. 2005. Clinical studies on the evaluation of doxorubicin as an adjuvant chemotherapy for the management of canine mammary neoplasms. M. V. Sc. Thesis, Punjab Agricultural University, Ludhiana.

Chandratre, G. A., Jangir, B. A., Saharan, S., Sharma, S. and Rath, A. P. 2017. Diagnosis of canine transmissible venereal tumour. Intas Polivet, 18(1):196-199.

Das, A. K., Das, U. and Das, D. 1991. A clinical report on the efficacy of vincristine on canine transmissible venereal sarcoma. Indian Vet J., 68:249252, 575-576.Moulton, J. E., Taylor, D. O. N., Dorn, C. R. and Andersen, A. C. 1970. Canine mammary tumours. Path. Vet. 7: 289-320.

Dhami. M. A., Tank. P. H., Karle. A. S., Vedpathak. H. S. Bhatia. A. S. 2010. Epidemiology of canine mammary gland tumours in Gujarat. Veterinary World, 3(6): 282-285.

Dileepkumar, K. M., Maiti, S. K., Kumar, N. and Zama, M. M. S. 2014. Occurrence of canine mammary tumours. Indian $J$. Canine Pract., 6(2): 179-183.

Egenvall, A. Bonnett, B. N., Ohagen, P., Olson, P., Hedhammar, A. and von Euler, H. 2005. Incidence of and survival after mammary tumours in a population of over 80,000 insured female dogs in Sweden from 1995 to 2002. Preventive Veterinary Medicine., 69:109-127.

Eze, C.A., Anyanwu, H.C., Kene, R.O.C. 2007. Review of canine transmissible venereal tumour (TVT) in dogs. Nigerian Vet J, 28(1): 54-70.

Ganguly, B., Das, U. and Das, A. K. 2016. Canine transmissible venereal tumour: a review. Veterinary and Comparative Oncology, 14(1):1-12.

Gupta, K., Sood, N., Uppal, S., Mohindroo, J., Mahajan, S., Raghunath, M. and Singh, K. 2012. Epidemiological studies on canine mammary tumour and its 
relevance for breast cancer studies. Journal of Pharmacy. 2(2):322-333.

Khan, L.A., Khante, G.S., Raut, B.M., Bodkhe, A.M., Chavan M.S., Pagrut, N.S. and Bobde, S. P. 2009. Incidence of venereal granuloma and its medicinal treatment in stray dogs of Nagpur City. Veterinary World, 2(1):13-14.

Kisani, I. A. and Adamu, S. S. 2009. A case of transmissible venereal tumour in a castrated dog in Benue state, Nigeria. Journal of Animal \& Plant Sciences, 5(2):527-530.

Kishor, T. K., Rao, S., Satyanarayana, M. L., Narayanaswamy, H. D., Byregowda, S. M., Nagaraja, B. N., Purushotham, K. M. and Kavya, N. 2016. Classification and staging of canine mammary gland tumours. Journal of Cell and Tissue Research Vol., 16(3):5787-5792.

Kose, A. M., Cizmeci, S. U., Aydin, I., Dinc, D. A., Maden, M. and Kanat, O. 2013. Disseminated metastatic transmissible venereal tumour in a bitch. Eurasian $J$ Vet Sci., 29(1):53-57.

Lather, D., Gupta, R. P. and Jangir, B. L. 2017. Pathological and immunohistochemical studies in mammary gland tumours affecting male dogs. Indian J. Vet. Pathol., 41(2):8993.

Mahopatra, H. K., Panda, S. K., Nath, I., Bose, V. S. C. and Patanayak, D. K. 2005. Occurrence of tumours in dogs. Indian Vet. J., 82:134-136.

Manjunatha, D. R., Mahesh, V. and Ranganath, L. 2013. Surgical management of mammary adenocarcinoma in a German shepherd dog. Intas Polivet., 14(I):165-166.

Moulton, J. E. 1999. Tumours in Domestic Animals. 3rd edn, University of California Press, Berkley, pp:518-543.

Nak, D., Nak, Y., Cangul, I. T. and Tuna, B. 2005. A Clinicopathological study on the effect of vincristine on
Transmissible Venereal Tumour in dogs. Journal of Veterinary Medicine Series A: Physiology, Pathology, Clinical Medicine., 52:366-370.

Nithya, P. 2006. Molecular marker studies in canine mammary tumours. M.V.Sc Thesis. Tamilnadu Veterinary and Animal Sciences University. Chennai.

Palta, M. K. 2000. Clinical studies on multimodality in the management of canine mammary neoplasm. M.V.Sc. Thesis, Punjab Agricultural University, Ludhiana.

Petrov, E. A., Ilievska, K., Trojacanec, P., Celeska, I., Nikolovski, G., Gjurovski, I. and Dovenski, T. 2014. Canine mammary tumours - clinical survey. Mac Vet Rev., 37(2):129-134.

Prasad, A. A., Vijayanad, V., Rajasundaram, R. C. And Balachandran, C. 2007. Cutaneous transmissible venereal tumour in a dog. Indian Vet J., 84:978979.

Priya, S., George, V. T., Balachandran, C. and Manohar, B. M. 2006. Incidence of canine mammary tumors in Chennai, Tamil Nadu. Indian Vet., J., 84:10541056.

Rutterman, G. R., Withrow, S. J. and MecEwen, W. G. 2000. Tumours of the mammary gland. In: Small Animal Clinical Oncology. $3^{\text {rd }}$ edn. Philadelphia WB Saunders Co. pp: 450-467.

Shafiee, R., Javanbakht, J., Atyabi, N., Kheradmand, P., Kheradmand, D., Bahrami, A., Daraei, H. and Khadivar, F. 2013. Diagnosis, classification and grading of canine mammary tumours as a model to study human breast cancer: an clinico cytohistopathological study with environmental factors influencing public health and medicine. Cancer Cell International. 13:79.

Sharma, A. K., Kumar, H., Choudhary, C. K. and Das, L. L. 2011. Hematobiochemical changes in dogs 
affected with transmissible venereal tumour. Indian J. Vet. Med., 31(1):2627.

Shiju Simon, M. S., Gupta, C., Sankar, P., Ramprabhu, R., Pazhanivel, N., Balachandran, C. and Prathaban, S. 2016. Incidence of transmissible venereal tumours in dogs- a survey of 278 cases. Indian Vet. J., 93(9):72-73.

Shivani. 2007. Cytopathology of canine mammary gland affections with special reference to mammary gland tumours. M. V. Sc. Thesis, GADVASU, Ludhiana, India.

Sorenmo, K. U., Rasotto, R., Zappulli V. and Goldschmidt, M. H. 2011. Development, anatomy, histology, lymphatic drainage, clinical features, and cell differentiation markers of canine mammary gland neoplasms. Vet.
Pathol., 48(1):85-97.

Sowbharenya, C., Dharmaceelan, S., Kumaresan, A. and Subramanian, M. 2016. Incidence and glandular distribution of canine mammary Neoplasms. Indian Vet. J., 93(11):2728.

Stockman, D., Ferrari, H. F., Andrade, A. L., Lopes, R.A., Cardoso, T. C. and Luvizotto, M. C. R. 2011. Canine transmissible venereal tumour: Aspects related to programmed cell death. Braz $J$ Vet Pathol., 4(1):67-75.

Tella, M. A., Ajala, O. O. and Taiwo, V. O. 2004. Complete regression of Transmissible venereal tumour (TVT) in Nigerian mongrel dogs with vincristine sulphate chemotherapy. Afr. J. Bio. Med. Res., 7(3):133-138.

\section{How to cite this article:}

Nutan Panchkhande, Rukmani Dewangan, M.O. Kalim, R. Sharda, H.K. Ratre, Dhlaeshwari Sahu, Shiv Sidar and Yadav, S.K. 2019. Incidence of Mammary Tumour and Venereal Granuloma in Canine in Durg District Chhattisgarh, India. Int.J.Curr.Microbiol.App.Sci. 8(04): 2368-2381. doi: https://doi.org/10.20546/ijcmas.2019.804.276 